\title{
En el nombre de la madre: hacia un paradigma pospatriarcal
}

\author{
(In the Name of the Mother: \\ toward a Pospatriarchal Paradigm)
}

\author{
Maria J. BINETTI
}

Recibido: 30 de noviembre de 2011

Aceptado: 27 de marzo de 2012

\section{Resumen}

Durante más de 3000 años, las religiones patriarcales han simbolizado un sistema socio-político e ideológico, que dominó hasta hoy la historia universal. Sin embargo, desde hace por lo menos dos siglos, el pensamiento y la cultura vienen anunciando la muerte del Dios Padre e indagando el destino de la humanidad futura. El presente trabajo intentará mostrar por qué la Gran Diosa Madre simboliza el Otro Nombre, en el cual la subjetividad y la cultura han comenzado a pronunciarse.

Palabras clave: Simbólica, mitología, religión, subjetividad, origen, feminismo.

\begin{abstract}
During more than 3000 years, patriarchal religions have symbolized a sociopolitical and ideological system, which dominated the history of the word up today. Nevertheless, since at least 2 centuries, the thinking and culture are announcing the death of God Father, and inquiring the destiny of the future humanity. The current paper aims at showing why the Great Goddess Mather symbolized the Other Name, in which subjectivity and culture have begun to pronounce themselves.
\end{abstract}

Keywords: Symbolical, mythology, religion, subjectivity, origin, feminism. 


\section{Introducción: la efectividad política de lo simbólico-religioso}

Si el ser humano es un animal simbólico, él es esencialmente un animal religioso. Tal es así porque la simbólica religiosa expresa el sentido fundacional, decisivo y último de lo real, actualizado al modo de una alianza o re-alianza con el origen y fin de todas las cosas. Que la religión constituya el acontecimiento sym-bálico ${ }^{1}$ del cual habla E. Trías significa por lo menos tres cosas: que hay un mundo fáctico, otro mundo de sentido y la posibilidad necesaria de su unidad, revelada e instituida religiosamente. De este modo, la simbólica religiosa tiene por vocación fundamental recrear el mundo de los hechos en su sentido último y fundacional.

El hecho de que toda simbólica contenga un sentido implícito, indica que ella constituye en sí misma una ideología, reconciliada de una u otra manera con los hechos que la sostienen. Y si además ese sentido nunca es disociable de su alianza con el acontecer empírico, entonces toda ideología es también política, vale decir, fuerza efectiva de construcción social, histórica, cultural, subjetiva. En una palabra, la simbólica religiosa es ideología y política a la $\operatorname{par}^{2}$, y lo es, en última instancia, en virtud de esa reciprocidad symbálica en la cual se intercambian ideas y realidades, sentidos y hechos, divinidades y humanidades. Esta unidad habilita a la religión como vía de acceso al pensamiento y la cultura de una época histórica.

De aquí entonces que toda formación religiosa comporte una racionalidad ideológica y política particular, y lo que nos interesa en este caso consiste en destacar el pensamiento y la cultura implícitos en la religión, o mejor, en las religiones del Dios Padre, donde principio, fin y valor tienen un sentido determinado. En efecto, el "Nombre del Padre" constituye el significante por antonomasia de un sistema socio-político y filosófico, que durante más de 3000 años ha dominado el modo de pensar, sentir y obrar universales. Pero además, lo que nos interesa en este caso se extiende también a otro nombre muy anterior, que durante más de 300000 años 3 auspició el modo de pensar, sentir y hacer de la humanidad. Efectivamente, la historia del Padre fue precedida por la prehistoria de la Madre, cuyo Nombre implica otro orden socio-cultural y otra construcción subjetiva.

Entre la simbólica de la Madre y la simbólica del Padre mediaron políticamente la persecución, la guerra y la masacre. Los vencedores impusieron, junto con su gobierno, también sus panteones, mientras que las Diosas eran forzadas -diría $\mathrm{H}$. Heine- al destierro. Sin embargo, lo desterrado siguió vivo, en la trama secreta de la noche, el deseo y lo inconsciente; en el goce reprimido, la nostalgia de la tierra y la exhuberancia vital, soñaba la Diosa. Y lo cierto es que hoy, después de casi 4 milenios, las Diosas vuelven del destierro.

\footnotetext{
1 Trías (2001), pp. 17 ss.; Trías (2006), pp. 33 ss.

2 Cf. Bourdieu (2010).

3 Aludimos aquí a la fecha de la cual datan las primeras Venus achelenses halladas hasta la fecha, a saber, la Venus de Tan-Tan y Berejat Ram.
} 
La propuesta de las siguientes páginas consiste en una suerte de análisis comparado entre ambas alternativas simbólicas, vale decir, entre el Nombre del Padre y el Nombre de la Madre. Con esto, no intentamos oponer binariamente un paradigma socio-cultural a otro, sino más bien deconstruir algunos elementos ideológicos que han instituido una simbólica a costa de la otra. Tal deconstrucción pondrá al descubierto un paradigma ancestral, sobre cuya negación se instauró el patriarcado y hacia cuya recuperación dialéctica parecería orientarse el futuro superador de $l x$ humanx.

\section{La simbólica del Padre: religión, filosofía y moral}

El Nombre del Padre es consistente con una organización socio-política, fundada en el poder y la autoridad masculinas, y construida sobre el orden jerárquico y excluyente de las diferencias. Las religiones del Padre -y aludimos con esto especialmente a la religión cristiana, aunque no únicamente a ella- reproducen y justifican con su mítica las relaciones de poder que la fuerza de los hechos ha consolidado.

Respecto de las divinidades originarias -teutónicas, impersonales y panteístasla institución del Dios Padre -celestial, personal y único- implicó el pasaje al monoteísmo religioso, instituido y sostenido por un cuerpo sacerdotal, que se legitimaba a su vez por dicha institución. En manos de sus sacerdotes, lo religioso fue teóricamente dogmatizado y prácticamente moralizado, a la manera de una voluntad inapelable. P. Bourdieu comenta al respecto que tal constitución intrínseca de lo religioso no está presente en las sociedades neolíticas y que ella es producto de culturas posteriores, jerarquizadas por un ordenamiento de clases y divididas según el trabajo ${ }^{4}$. La clase sacerdotal del Dios Padre convirtió entonces la religión en una cuestión dogmática y legalista 5 , estableciéndose a sí misma como criterio entre lo bueno y lo malo, lo sagrado y lo profano, los justificados y los réprobos, los varones y las mujeres.

Junto con la racionalización y moralización, hay un tercer elemento que determina a las religiones patriarcales, a saber, su militarización6. En efecto, el poder eclesiástico es un poder armado, cuyas milicias se justifican teóricamente por el mantenimiento del orden moral y prácticamente por la consolidación de su poder económico. Bajo la bíblica presunción de que Yavé es un Dios celoso, fue convalidada la guerra, la explotación económica y la inquisición, mediante las cuales el celo del único Dios verdadero se aseguraba la exclusividad. A tal precio fueron eliminados los cultos autóctonos, las viejas creencias telúricas, los rituales lunares, las

\footnotetext{
4 Cf. Bourdieu (2010), p. 52.

${ }^{5}$ Cf. Bourdieu (2010), p. 53; Trías (2001), p. 61.

6 Cf. Sjöö - Mor (1991), pp. 263 ss.
} 
prácticas de la adivinación, la magia y la brujería, todos ellos ejercidos por mujeres. P. Bourdieu explica que la demonización y descalificación religiosa de tales ritos y creencias, típicamente femeninos, disimula la dominación política y económica de la clase sacerdotal masculina ${ }^{7}$.

Otra característica de las religiones patriarcales consiste en el orden sucesorio de sus sacerdotes, soldados y profetas, a través del cual se mantiene la genealogía del padre. Los tres grandes monoteísmos históricos, a saber, judaísmo, cristianismo e islamismo, se conservan en virtud de una tal sucesión, que establece cuidadosamente la pureza de la estirpe patriarcal, asegurándose la exclusión de toda intervención materna o, mejor dicho, asegurándose su apropiación. Dios pacta su alianza con los varones y entrega su poder de Padre a Hijo, observando que la madre sea o bien diabólica, o bien sierva y virgen. De Abraham a Moisés y Mahoma, de San Pedro a Benedicto XVI, la autoridad del padre se transmite de varón a varón y exige como condición de posibilidad la eliminación de la genealogía materna.

Hasta aquí, podríamos decir que las grandes religiones del Padre se han constituido como sistemas socio-políticos jerárquicos, dogmáticos y fundamentalistas. Su origen histórico y geográfico hay que buscarlo hacia el $2500 \mathrm{a}$. C, cuando los pueblos arios del norte europeo y el Caúcaso comenzaron a invadir el sur de Europa y el cercano oriente, trayendo consigo sus divinidades solares y guerreras. Entonces el paganismo europeo originario, con sus divinidades telúricas y su profusión vital y sensible, era desterrado por los ejércitos sacerdotales del Dios Sol, devenido Padre, Rey y Juez de la humanidad.

Los sistemas religiosos patriarcales son consistentes con una ideología teológica, filosófica y moral, en la cual definen el sentido del mundo y de la existencia humana. Si míticamente representado Dios es Padre, Señor, Rey y Juez del universo, tales características trasvasan al dominio metafísico en una suerte de teísmo onto-teo-lógico, que interpreta a Dios como el ser absoluto, a su vez personal, racional y libre. Filosóficamente, Dios es la Sustancia que trasciende el mundo, simple e idéntica a sí misma, perfecta e inmóvil, infinita, eterna y omnipotente. Además, en tanto que persona libre y racional, él es absolutamente sabio, bueno, justo y amoroso. En virtud de su perfección absoluta, Dios descansa en su plenitud e integridad, más allá de todas las cosas, y esto significa que sin el mundo, Dios sigue siendo perfectamente el mismo Dios, porque se basta a sí mismo en su sustancialidad inmutable y ultramundana.

Desde este ser eterno e inmutable, Dios crea el mundo, afirmándose así como causa incausada y exclusiva de todas las cosas, incluida la madre. La doctrina monogenética del Padre asegura la creación ex nihilo - de la nada- de todo por su omnipotencia, y valga el comentario de que en esta nada, algunos historiadores con-

7 Cf. Bourdieu (2010), p. 59. 
jeturan el lugar de las antiguas divinidades femeninas ${ }^{8}$. El Padre no engendra en y por su propio cuerpo, porque él es inmaterial e infértil. Por el contrario, Él crea de la nada, en la discontinuidad de sí mismo y la caída de su perfección. La teoría de la creación ex nihilo niega una relación directa, natural y continua con el elemento divino del ser, e instaura la nada como instancia mediadora entre Dios y el mundo, ambos totalmente otros. De este modo, se explica el dualismo entre el Creador -eterno, absoluto, perfecto- y lo creado -temporal, finito, imperfecto-, dualismo que, habida cuenta del carácter imperativo y moralizante de la ideología patriarcal, deviene por su propio peso la diferencia entre el bien y mal. Entre Dios y el mundo, el ser eterno y el ser finito, media la nada, especificada moralmente como caída, pecado, culpa, y atribuida a la responsabilidad del hombre o, rigurosamente dicho, a la responsabilidad última de la mujer.

En el principio es entonces el Padre Omnipotente, creador de todas las cosas, que han caído al mundo de lo finito y temporal por el pecado de la mujer. La idea de pecado expresa un dualismo fundacional e insuperable entre Dios y el ser humano, entre su infinitud trascendente y la existencia finita. Trascendencia y dualismo constituyen el contrapunto filosófico de una relación religiosa abstracta, alienada y moralista con un Dios lejano, ajeno a la creación y, mucho peor, impávido frente a una creación pecadora y maldita. Según la mitología bíblica, el pecado de la mujer inaugura la historia humana con la expulsión del paraíso, la maldición de la procreación femenina y la condenación de la vida al trabajo, la enfermedad y la muerte. A partir de aquí, el sentido de la existencia humana consistirá en saldar la culpa de haber nacido y en recuperar el beneplácito del Padre a costa de la propia vida.

Desde el punto de vista subjetivo, el sistema patriarcal dispuso la internalización de la culpa y el castigo a través de instancias psíquicas - conscientes e inconscientes- de represión, autonegación y autocontrol. El legalismo moral y religioso quedó de ese modo sancionado por la propia subjetividad, en la estructura de un super-yo ideal, culpógeno e imperativo. El Nombre del Padre, dispuesto ahora de manera inconsciente en el poder superyoico de la personalidad, ordenó íntimamente la represión de los impulsos vitales y prohibió el deseo, la pasión, el éros, la sexualidad. Nuevamente aquí, el dualismo quedó instituido en la intimidad psíquica del sujeto, escindida ahora entre sus impulsos vitales, pecaminosos y bajos, y los nobles y trascendentes ideales del deber ser. La oposición deseo / deber, pasión / prohibición determinó de este modo la autonegación del yo patriarcal.

El precio que la intimidad emocional del sujeto debió pagar por reconquistar los favores del Padre no fue poco. Su costo implicó la pérdida de la energía vital, la desconexión consigo mismo y con el mundo, y la sanción del dolor como horizonte de sentido. La vitalidad reprimida psicológicamente reapareció como muerte, agre-

\footnotetext{
8 Cf. Tubert (1991), p. 67.
} 
sión, guerra, autocastigo. En este sentido, E. Whitmont comenta que "el ideal patriarcal del yo se funda sobre tres pilares básicos: 1) la eficiencia de la voluntad; 2) la posesión; 3) el honor, la fama, el rango y la estima en la jerarquía de la comunidad [...] Él crea su identidad a través de la voluntad, la manipulación, la fuerza sobre el objeto, en una palabra, la agresión"9. La autoagresión inflingida por la subjetividad culpógena y superyoica se desplazó socialmente hacia los ideales del heroísmo, la guerra, el coraje, cifrados todos ellos bajo el común denominador de la muerte. En consecuencia, el yo patriarcal obtiene su reconocimiento social en la lucha a muerte por el señorío, que hace amos y esclavos al mismo tiempo.

Recapitulando lo dicho hasta aquí, la simbología religiosa patriarcal, entretejida por la clase dominante de algunos varones, se determina por el carácter exclusivo y excluyente de un Dios terrible, celoso e imperativo. El Dios bíblico es el Rey que ordena la guerra y la masacre de los enemigos, el Juez que entrega las tablas de la Ley y, finalmente, el Padre que ordena la muerte de su Hijo como acto heroico fundacional de la redención humana. Desde su cielo ideal, el Señor legisla e impera, maldice la tierra y ofrece la salvación eterna a cambio del sacrificio temporal. Esto mismo tuvo su correspondiente filosófico en la representación de un absoluto, sustancial y personal, trascendente a todo lo finito y mutable. La trascendencia de la perfección divina supuso el dualismo metafísico, en virtud de cual quedaron irreconciliablemente escindidos eternidad y tiempo, bien y mal, luz y oscuridad, razón y sentimientos, masculinidad y feminidad, identidad y diferencia. Este mismo dualismo se instaló tanto en la intimidad subjetiva como en orden social, ambos regidos por la razón del amo y el esclavo.

Políticamente, el Nombre del Padre justificó y reprodujo una sociedad jerárquica, fundada en el derecho de uno y el sometimiento de todos los demás, empezando por las mujeres. La conclusión no podía ser otra, una vez que, eliminada la genealogía materna, el hijo siempre debe demostrarle al padre una legitimidad, que jamás termina de convencerlo.

\section{La simbólica de la Madre: religión, filosofía y moral}

Si en el origen de la historia fue el Padre, en los orígenes prehistóricos era la Madre con su simbólica, su genealogía, su ordenamiento universal y su comprensión subjetiva. De esta prehistoria da testimonio la arqueología y el hallazgo de una enorme cantidad de pequeñas estatuillas, de entre los 3 y los 30 centímetros, de mujeres generalmente obesas o embarazadas, con enormes pechos y vientres, vulvas y nalgas exagerados, sin rastros faciales y con extremidades poco definidas. Estas figuras, así llamadas Venus, cubren prácticamente toda Europa y Asia, y se

\footnotetext{
9 Whitmont (1982), pp. 217-218.
} 
remontan al paleolítico inferior. Hacia fines del siglo pasado fueron descubiertas las Diosas Madres paleolíticas más antiguas -las Venus achelenses de Berejat Ram y de Tan Tan-, que los estudios datan de unos 300000 años. Más conocidas y abundantes son sin embargo las Diosas Madres del paleolítico superior, de unos 40000 o 30000 años, la más famosa de cuales es la Venus descubierta en Willendorf.

Las Diosas Madres paleolíticas dan cuentan de la fecundidad femenina, la maternidad, como el primer objeto de culto y veneración que se conoce. La acentuación hiperbólica de las partes del cuerpo femenino relacionadas con la fertilidad sugiere una interpretación mágica o numinosa del embarazo, de manera tal que fecundidad y maternidad no significaron originariamente un hecho biológico, sino un poder mágico, místico, divino, sagrado. De allí que sea posible concluir que "la capacidad de crear vida de la mujer es la base del misterio"10. El carácter sagrado de la fecundidad femenina, su potencia mágico-religiosa, representada en las pequeñas Diosas paleolíticas, se transformará en las grandes divinidades maternas del período neolítico posterior.

El período neolítico constituye el testimonio más accesible y patente del prestigio social de las mujeres en los tiempos arcaicos y que cristalizó en las religiones maternas. La Gran Diosa Madre representó la suprema deidad de ese período, cuyos templos se esparcieron por toda Europa, el último de los cuales fue clausurado hacia el 500 d. C.11. El descubrimiento de la agricultura durante el neolítico hizo que la función procreadora de la madre fuera asociada a la fecundidad de la tierra, y el culto de la fertilidad femenina se vinculara al culto de la fertilidad de los cultivos ${ }^{12}$. Algunos autores hablan de la relación mujer-tierra como la primera analogía humana ${ }^{13}$, establecida en la intuición primaria de la fecundidad como poder divino. Ese fue también el origen de la fe y la esperanza de la humanidad: la fecundidad de la mujer, las mieses, las especies vivas. De allí los numerosos rituales de invocación a las deidades femeninas, generalmente a cargo de sacerdotisas, a fin de obtener los frutos del vientre materno y de la tierra. Estos cultos religiosos preceden toda racionalización, dogmatización y moralización de lo divino, y coinciden con la veneración de la vida, la tierra, la renovación y sexualidad, mediante ritos orgiásticos o sensuales ${ }^{14}$.

En síntesis, desde la prehistoria inmemorial hasta los comienzos históricos, la divinidad era Madre y Mujer. Tal no representa una persona individual sino una fuerza impersonal, primordial, originaria: la fecundidad femenina, el poder procreador, la energía vital, el seno nutricio y protector, lo fértil, el nacimiento, las mie-

\footnotetext{
10 Sjöö - Mor (1991), p. 71.

11 Cf. Stone (1978), p. XII.

12 Cf. Preston (1982), p. 330.

13 Cf. Sjöö - Mor (1991), p. 47.

14 Cf. Trías (2001), p. 66; Stone (1978), p. XVIII-XIX.
} 
ses. Esta determinación de lo divino por su función fecunda, vital y nutricia sigue presente en las religiones populares de todo el mundo15. La humanidad primitiva adora la vida, y adora lo materno como su posibilidad, origen y sustrato. Para el inconsciente prehistórico, en el principio es "la entraña cuya eclosión produce un cosmos" 16 , y lo específico de esta gran matriz universal es que ella concibe y conserva en sí misma, en su propia inmanencia material y viva. Lejos de la trascendencia absoluta del padre, de su discontinuidad y oposición dualista, la simbólica materna se fundan en la experiencia de una totalidad monista, de una suerte de "continuo mágico"17, respecto del cual el vientre materno ofrece la imagen más originaria.

Brevemente, quisiéramos enunciar aquí algunos de los rasgos determinantes de esta simbólica materna, tanto en su dimensión religiosa, como metafísica y subjetiva. En primer lugar, y a diferencia de la mítica patriarcal -donde el Padre crea de la nada, el polvo o el barro-, "en los mitos más antiguos de la creación del mundo, la Diosa mujer crea el mundo de su propio cuerpo"18. La madre concibe por y en su propia materialidad, capaz de diferenciarse, multiplicarse y expandirse ilimitadamente. De aquí la imagen del seno o el útero materno como receptáculo y matriz universal, del cual todo surge y al cual todo vuelve; y la idea del regressus ad uterum $^{19}$ como símbolo de los rituales de iniciación y renacimiento espiritual. La inmanencia del seno materno, trasvasada al continente universal de todas las cosas, "satisface el anhelo de un estadio indiferenciado de la existencia"20. Y este anhelo inconsciente, donde sujeto y objeto son uno, y donde la diferencia es identidad, este deseo simboliza el sustrato originario y prehistórico no solo de la humanidad, sino de cada existencia singular.

El hecho de que la madre engendre en y por sí misma supone que su materialidad es una fuerza activa, positiva, afirmativa ${ }^{21}$, y sólo como acción creadora ella puede asegurar el sustento, la vida y la transformación de todo. Sin embargo, justamente por ser capacidad o posibilidad activa de poder, ella es también capacidad activa de no poder, vale decir, fuerza destructora. En esto reside el carácter ambivalente atribuido al poder matricial: tan creador y nutricio como salvaje, fiero y tenebroso 22. Para el imaginario arcaico, "las deidades femeninas están cargadas de paradojas, combinan opuestos tales como el amor y el odio, la confianza y el terror, el

\footnotetext{
15 Cf. Preston (1982), p. 330.

16 Trías (2006), p. 63.

17 Whitmont (1982), p. 45.

18 Sjöö - Mor (1991), p. 49.

19 Cf. Eliade (1975), pp. 79 ss.

20 Duby - Perrot - Schmitt Pantel (1994), p. 36

21 Cf. Trías (2006), p. 85.

22 Cf. Trías (2006), p. 77.
} 
perdón y la venganza" 23 . La madre que concibe y nutre es la misma que destruye y entierra; su seno significa nacimiento y tumba, fertilidad y fin, porque si a ella le pertenece la vida, a ella también le pertenece la muerte. Sólo así, la madre representa la totalidad, capaz de contener en su ambivalencia y contradicción la multiplicidad y el cambio. El principio materno es en sí mismo ambiguo, múltiple y contradictorio, y es por eso "poder de transformación"24. Fuente de la vida y el cambio, su poder transformador sigue un ritmo cíclico: los ciclos menstruales, estacionarios, lunares; los cultivos y la vida humana alternan cíclicamente.

La simbólica materna, con seno fecundo y nutricio, supone una metafísica de la identidad diferencial, dialéctica e inmanente. En efecto, aquel representa la unidad del fundamento, que genera y sostiene su propia contradicción y diferencia. La experiencia del seno materno es la experiencia del todo y la continuidad; y la relación materno-filial, originaria, inmediata y fundante, constituye la metáfora de la reciprocidad entre ser y pensar ${ }^{25}$. Cuando la identidad diferenciada del continuo materno constituye el modelo último de lo real, entonces quedan superados los grandes dualismos trascendentes, las exclusiones binarias y las oposiciones irreconciliables. Según la metafísica de la madre, en el origen es la inmanencia de la totalidad, una, indiferenciada e indeterminada: caos amorfo, abismo insondable, fondo tenebroso y noche oscura son todas ellas metáforas de ese sustrato matricial de lo real.

Porque en el origen es la indeterminación activamente concebida como posibilidad de lo múltiple, resulta que en el origen es también la contradicción y el dinamismo. En otras palabras, en el origen es la dialéctica de lo uno que se determina como dos, y recupera su identidad en la reciprocidad amorosa de la relación maternal. La identidad del principio matricial se concibe en su propia diferencia, y de este modo hace posible la emergencia de lo otro en el corazón de sí misma. De aquí que ella sea en rigor "una triplicidad"26: ni lo uno ni lo otro, sino la relación de ambos en un tercer término de permanencia, mediación y unidad, que se dice reciprocidad amorosa. En este sentido, algunas autoras aseguran que "la gran Diosa era siempre una triplicidad: permanencia entre todas las elecciones dualistas y todas las oposiciones - un tercer termino que mediaba y sintetizaba las polaridades en una nueva cosa, una epifanía: la inmanencia de la trascendencia, la trascendencia de la inmanencia"27. La identidad continua y diferencial del principio materno, o bien, su triplicidad relacional y amorosa, fundan la existencia como contradicción, flujo, devenir, creación libre.

\footnotetext{
23 Preston (1982), p. 331.

24 Getty (1990), p. 49.

25 Muraro (1994), pp. 73, 89.

26 Sjöö - Mor (1991), p. 407.

27 Sjöö - Mor (1991), p. 407.
} 
La inmanencia materna como paradigma metafísico expresa también la conciencia divina y religiosa de la vida, la tierra, la exhuberancia sensible y emocional, lo instintivo 28 . El deseo, la pasión, lo sexual y la materia son valorados y venerados como fuerzas anímicas, numénicas, sagradas, de manera tal que, lejos del dualismo que opone la pureza del espíritu a la inmundicia de la carne, la simbólica materna reconoce su identidad esencial y su sacralidad de origen. Algunas intérpretes remiten la experiencia de lo uno a lo específico de la constitución femenina, como si fuera "la mujer la designada por la evolución como el vínculo entre sexualidad y espíritu, entre energía biológica y alma cósmica. La mujer, como líder de la evolución de la tierra, fue específicamente y neurológicamente estructurada para la experiencia de éxtasis" 29 . Pero sea o no prenda esencial de la mujer, lo cierto es que la experiencia extática primitiva, consagrada como rito divino, orgiástico y sensual, supone una suerte de monismo metafísico, respecto del cual el seno materno resulta ejemplar.

La experiencia religiosa, metafísica y subjetiva de las sociedades prehistóricas está testimoniada por documentos y fuentes culturales, en el inconsciente colectivo y el sentir más íntimo de lo humano. Conocida es la teoría de J. Bachofen sobre un primer período de la humanidad, centrado en el derecho materno y organizado socialmente según un modelo ginecocrático ${ }^{30}$. Su tesis sobre un gobierno originario de las mujeres, una suerte de matriarcado primitivo, se inspira en Egipto y, concretamente, en el tratado de Plutarco sobre Isis y Osiris. Con respecto a la tesis de Bachofen sobre un derecho sucesorio en línea materna, es decir, sobre una matrilinealidad anterior al derecho del padre, la opinión de los estudiosos ha sido ampliamente afirmativa ${ }^{31}$. Por el contrario, su tesis sobre un matriarcado primitivo, donde las mujeres ejercerían el gobierno sobre los varones, ha sido "casi universalmente desacreditado"32. Antropólogos e historiadores coinciden en que la simbólica materna y el orden sucesorio matrilineal no demuestran un matriarcado ${ }^{33}$, no al menos en tanto que construcción socio-política simétricamente opuesta al patriarcado. Este supuesto matriarcado, una especie de duplicado patriarcal de sexo inverso, nunca existió históricamente ni lógicamente podría existir, porque la eficacia simbólica de la Madre legitima y produce otro orden de sociedades y subjetividades, donde poder y autoridad significan algo distinto a lo que el Padre entiende por tal.

Lejos de constituir un matriarcado, la evidencia prehistórica muestra que las sociedades auspiciadas por divinidades maternas y cultos femeninos son igualitarias

\footnotetext{
28 Cf. Jaggar - Young (1998), p. 229.

29 Sjöö - Mor (1991), p. 429.

30 Cf. Bachofen (1992).

31 Cf. Eliade (1975), p. 456.

32 Preston (1982), p. 326.

33 Cf. Preston (1982), p. 326.
} 
y pacíficas ${ }^{34}$, tal como aconteció durante los períodos del paleolítico y el neolítico. La así llamada revolución neolítica, por la cual el mundo conoció la agricultura, el pastoreo y la alfarería, la curación mediante hierbas y la escritura, esa revolución "fue creación de la mujer"35. Las sociedades del neolítico ignoran la violencia, la explotación, las jerarquías y las dominaciones ${ }^{36}$. A imagen y semejanza de sus divinidades femeninas, que no saben de conquistas ni expansiones territoriales ${ }^{37}$, estos pueblos carecen de fortificaciones y armas ${ }^{38}$, y no hay en ellos signos de violencia, guerra, invasión o robo. El interés de estas sociedades consiste en afirmar, cuidar y venerar la vida ${ }^{39}$, tanto como sus divinidades monitoreaban y protegían los ciclos vitales del nacimiento y el fin ${ }^{40}$. La paz prevalecía entonces, fundada en la armónica disposición de las diferencias. Sobre esta armonía se basa el orden moral de las culturas neolíticas, cuyos conflictos se resuelven por el intercambio, la alternancia y el equilibrio de fuerzas. La ley del más fuerte, la agresión y la violencia como expresión de poder y autoridad no son criterios éticos de las sociedades matrilineales, instituidas más bien en el valor ético de la vida, la fecundidad y el equilibrio.

Las culturas neolíticas constituyen el mejor documento prehistórico de la simbólica materna, pero no son el único testimonio. Junto con aquellas, también la psicología empírica detecta en los así llamados arquetipos, ideas o fantasías inconscientes, las huellas matriciales de la humanidad. En este sentido, la Gran Madre constituye una realidad psíquica, determinada por su propia lógica emocional y anímica. Esta línea de indagación es la tarea del psicoanálisis y sobre tales conceptos afirma Jung: "entiendo pues por arquetipo una propiedad o condición estructural de la psique" 41 . En tanto que condición estructurante, el arquetipo organiza, regula y unifica el dinamismo psíquico, pauta su comprensión y su acción subjetivas. De aquí que no deba entenderse como una representación estática, o una idea o imagen intelectual, sino más bien como la energía, el impulso o la tendencia que precede todo el ámbito representativo, como la posibilidad activa de todo sentido y acción. Los arquetipos son las fuerzas elementales del aparato psíquico y de ellas derivan, a posteriori, las representaciones intelectuales de la conciencia. Entre estos arquetipos, se cuenta el arquetipo materno ${ }^{42}$, cuya presencia y operatividad es una constante psíquica universal ${ }^{43}$.

\footnotetext{
34 Cf. Preston (1982), pp. 326-327.

35 Sjöö - Mor (1991), p. 88.

36 Sjöö - Mor (1991), p. 90.

37 Cf. Whitmont (1982), p. VIII.

38 Cf. Motz (1997), p. 25.

39 Sjöö - Mor (1991), p. 90.

40 Cf. Whitmont (1982), p. VIII.

41 Jung (1961), p. 165.

42 Cf. Jung (1984), p. 95.

43 Cf. Jung (1961), p. 21.
} 
En tanto que arquetipo psíquico universal, la Gran Madre representa la fuerza una e idéntica de lo real, previa a la separación de la individualidad y a la discriminación consciente de todas las cosas. Esta instancia totalizadora es más íntima a la individualidad que la individualidad a sí misma, y de aquí que C. Jung le atribuya la mayor energía psíquica ${ }^{44}$, fuente de todo el dinamismo múltiple ulterior. Justamente por representar la energía originaria de lo real, una e indeterminada, la Gran Madre contiene implícitamente lo dual, contradictorio y ambiguo. Por un lado, ella es potencia de vida, amor, unidad; por el otro lado, es energía oscura, destructiva, abismal y mortífera ${ }^{45}$. En el orden de lo real, el arquetipo materno actúa como principio fundacional del cual todo surge y al cual todo vuelve; en el orden simbólico, constituye el significante primario de todo sentido y representación socio-cultural.

Pero lo cierto es que este arquetipo histórico-universal sólo existe y actúa cuando es asumido y repetido por la psiquis singular de cada individuo. Respecto de la subjetividad individual, la Madre emerge como el fantasma primitivo, inconsciente, previo a toda experiencia clara y discreta, y a toda historia personal. Respecto de la individualidad consciente, su habitación en el cuerpo materno, en la unidad continua con la madre, antes que la palabra verbalice el tiempo y el espacio, tal constituye el a priori de toda experiencia posible ${ }^{46}$, el sustrato de la diferencia, la separación y el sentido. La identidad inmediata del seno materno no es vivida por la psiquis individual como una más de sus experiencias empíricas, sino como la posibilidad última de todas ellas, la posibilidad de la posibilidad. La Madre es fuente y origen inmanente, que permanece en cada acción particular, como la razón última de su identidad y sentido. La pre-experiencia del seno materno no pertenece al pasado sino al presente, ella no fue sino que es actualmente, a cada instante, el continuo fundacional de toda discriminación finita, su sustrato último o, para decirlo en términos lacanianos, la Madre es constitutiva y esencialmente "lo real" 47 , establecido en el origen impensable, imposible e impersonal de toda experiencia psíquica presente. Desde esta identidad continua e inconsciente, el individuo ex - siste como puesto, lanzado, parido fuera de su fundamento. Psíquicamente considerado, lo arrojado o lanzado fuera es el deseo subjetivo -el éros-, constituido entre el recuerdo del goce primordial de la madre 48 y su ausencia. Arrojado fuera de su fundamento, el deseo dinamiza el aparato psíquico en su dialéctica continúa con la angustia. Deseo y angustia, dialécticamente tensionados, expresan la realidad de una totalidad perdida, negada, escindida en la individualidad. Ambos evocan, desde el dolor de su pérdida o el impulso hacia su recuperación, a esa Madre 49 de la cual surge y a la cual remite toda acción individual.

\footnotetext{
44 Jung (1984), p. 212.

45 Cf. Jung (1984), pp. 222-23.

46 Cf. Muraro (1994), p. 39; Tubert (2001), p. 128.

47 Tubert (2001), pp. 127-128.

48 Cf. Lacan (1992), p. 339.

${ }^{49}$ Cf. Tubert (2001), p. 131.
} 
Si en lugar de la experiencia disrelacional y alienante del Padre, se asume la pre-experiencia originaria e inmediata del seno materno como imagen y semejanza de lo humano, entonces el resultado es un modo de subjetivación propio y específico, que poco tiene que ver con la autoinmolación del super-ego patriarcal. En efecto, uno es el sentido de lo humano causado de la nada por un Padre trascendente y otro es el sentido de una subjetividad concebida y conservada en el seno inmanente de la madre. En este último caso, la conexión con la vitalidad, lo corpóreo, oscuro e irracional es inmediata, porque el continente físico, emocional y espiritual de la existencia está dado en y con ella misma. Este espacio de contención, dentro del cual irrumpe la individualidad, hace posible el juego de la vida. El seno materno contiene, afirma y cuida la separación, y entonces es posible jugar, porque el sentido de la vida está radicalmente garantizado.

Mientras que la separación del Padre engendra el deber y el hijo debe demostrarle su legitimidad; la separación de la Madre engendra el deseo y su re-ligación simbólica es lúdica, porque su afirmación es inmanente e incondicional. La madre garantiza a priori, con, por y en su propio cuerpo, la identidad del origen y la legitimidad de lo concebido, de aquí que toda subjetividad sepa inconscientemente que puede jugar en paz $^{50}$. En esto reside la felicidad que es el bien supremo de la ética materna: en el libre juego de la existencia. La convalidación absoluta de la vida, hace posible su resignificación ética en términos de un juego libre y creador. Si la ética patriarcal condiciona el valor al cumplimiento del deber, la ética del juego confirma el deseo, más allá del bien y del mal, y por eso "exige ante todo descubrir y convalidar lo que es" 51 . Para esta ética, la responsabilidad es el ser, y la culpa es prohibirle o negarle desear.

En conclusión, la simbólica materna representa la unidad del origen y la división de esa unidad; la identidad primigenia, y la diferencia engendrada y contenida por ella misma. Su dinamismo hace posible la dialéctica de la angustia, el deseo, el juego de la existencia. Ya se trate de los enormes senos de las Diosas Madres paleolíticas, del inconsciente colectivo o del fantasma primitivo de la subjetividad psíquica, todo apunta a una misma experiencia fundacional.

Pero lo cierto es que esta simbólica, sostenida en una profunda vivencia existencial, comenzó a diluirse ni bien comenzada la historia humana, hacia el $2500 \mathrm{aC}$, cuando las hordas invasoras del norte europeo comenzaron a esparcir sus dioses solares, viriles y guerreros por Europa y el Cercano Oriente. Entonces las Diosas Madres fueron dadas en matrimonio e incorporadas a un panteón de divinidades masculinas. Así, por ejemplo, el caso de Inanna en Sumeria, Ishtar en Babilonia, Anat en Canaán, Astarté en Fenicia, Sejmet en Egipto, Morrigan entre los celtas, Kali en el hinduismo, Gaia en Grecia, Tellus en Roma, Isis, Deméter, Ceres, etc. En

50 Cf. Whitmont (1982), p. 240.

51 Whitmont (1982), p. 248. 
el caso del Panteón griego, las Diosas se reparten los atributos femeninos entre "una Atenea - una intelectual asexuada- una Afrodita - un frívolo objeto sexual- y una respetable esposa y madre como Hera" 52 , con lo cual se impone el modelo de una existencia femenina restringida a alguna de esas incompatibles.

En los griegos también, para tomar como ejemplo el referente privilegiado de la tradición occidental, el principio matricial de todas las cosas fue depotenciado y convertido en un receptáculo inerte e improductivo, meramente pasivo y oscuro, al cual se le añadió la masculinidad del logos -la razón formal- como principio activo, determinante y luminoso. De este modo, la realidad quedó escindida en 2 principios, que la tabla pitagórica de los opuestos rigurosamente distingue: lo uno y lo múltiple, el reposo y el movimiento, lo determinado y lo indeterminado, lo recto y lo torcido, la luz y la oscuridad, lo bueno y lo malo, lo masculino y lo femenino. Impotencia, oscuridad, mal y mujer van en la misma línea. Trátese de la Gaia o la Noche en la Teogonía de Hesíodo, del arché presocrático - que curiosamente nunca es tierra-, de la chora platónica o de la materia prima aristotélica, en cualquiera de estos casos, el sustrato materno ya ha sido reelaborado por la razón formal, en los términos de una matriz oscura y pasiva, principio del mal, lo corpóreo y las pasiones.

\section{La muerte del Dios Padre y el retorno de un viejo paradigma}

Hace más de 3000 años, las Diosas fueron exiliadas de la humanidad, su simbólica, desterrada, y el sentido metafísico, religioso, subjetivo, etc. de lo materno fue reprimido. El declive socio-cultural de las grandes divinidades maternas coincidió con la emergencia de los dioses solares y la consolidación del sistema patriarcal, en función del cual se ha estructurado hasta hoy la historia universal.

Pero lo cierto es que, por lo menos a partir de la modernidad, el mismo devenir histórico que produjo su encumbramiento, comenzó a propiciar la caída del patriarcado en su doble valencia ideológica y práctica. Aunque la breve extensión de este trabajo nos impide detenernos en el itinerario especulativo que ha llevado a esa conclusión histórica, podemos al menos señalar que tal se relaciona con la construcción de una nueva subjetividad, absolutamente libre y creadora, concomitante con el modelo político de la igualdad democrática y con el modelo metafísico de un monismo dialéctico. En este sentido, las antiguas prerrogativas del Padre trascendente fueron cedidas a las nuevas prerrogativas del individuo autoconsciente y autónomo, sujeto de una libertad absoluta.

Los profetas y testigos del ocaso patriarcal abundan. Para mencionar solo algunos, ya los primeros idealistas románticos, aglutinados entorno a F. Schlegel, anunciaban el vaciamiento de lo divino y la necesidad de una nueva mitología religiosa,

52 Cf. Pomeroy (1987), pp. 22-23. 
a la altura de los nuevos tiempos ${ }^{53}$. Holderling soñaba con "el Dios venidero"54, mientras que Schelling y Novalis auguraban una religión del espíritu55. El hegeliano "viernes santo especulativo" precedió por casi un siglo al desconcierto de Nietzsche ante la muerte del Dios Padre. El pensamiento posmoderno se pregunta hoy al respecto "¿quién o qué viene luego? ¿después del funeral?”56 divino, a cuya respuesta se aviene la idea de una "religión sin religión" 57 , incardinada en la subjetividad pura. Tales testimonios dan cuenta de una realidad metafísica, religiosa, política, subjetiva, etc., respecto de la cual el viejo modelo del dualismo trascendente e imperativo ya no resulta identificatorio.

La muerte del Padre, la apelación a una subjetividad inconmensurable, la inmanencia del sentido, la resignificación de la carne y la sexualidad, y el proyecto de una existencia absolutamente libre, todo esto reclama y produce un nuevo paradigma identificatorio, consistente con el orden simbólico de la Madre. En este sentido, consideramos que el progreso histórico-especulativo de lx humanx se orienta a la recuperación del modelo femenino-materno en su experiencia una de sentido, en su mítica olvidada y en la exuberancia de su juego, siempre abierto. Los profetas y testigos de este nuevo paradigma también abundan.

Así por ejemplo, el pensamiento posmoderno ha denunciado el falocentrismo y falogocentrismo filosófico, y asegurado que "lo femenino, lejos de cualquier empiricidad, desempeña una función salvadora en el declive de la metafísica occidental"58. Tal es así porque, frente al dualismo del Padre, la inmanencia materna "nos plantea la cuestión de las relaciones entre lo Uno y lo múltiple", y la posibilidad de "otros modos de pensar la dualidad, la multiplicidad y la alteridad"59. La clave de este nuevo modo de pensar consiste, sin lugar a dudas, en la reciprocidad continua de lo uno con su diferencia. También desde el punto de vista religioso, la muerte del Padre abre el reclamo de nuevos "sistemas religioso-culturales capaces de invalidar la agresión, el odio y la violencia, y redireccionarlos a canales constructivos. No tenemos ninguno. Nuestras religiones tradicionales patriarcales no nos ayudan a contenerlos" 60 . Lo religioso como sistema jerárquico, infalible e inquisitorial resulta incompatible con el sentido de esa nueva subjetividad, autorreconocida en su libertad absoluta y en sus derechos inalienables. Tampoco se aviene con la subjetividad contemporánea el intercambio contractual de méritos y deméritos, premios y

\footnotetext{
53 Cf. Schlegel (1958), pp. 76-77.

54 Hölderlin (1979), II, pp. 64-65; I, pp. 232-233.

55 Trías (2001), p. 49.

56 Caputo (2002), p. 3.

57 Derrida (1999), p. 75 ; cf. también Caputo (1997).

58 Birulés (1995) p. 148.

59 Tubert (1997) p. 55.

60 Whitmont (1982), pp. 12-13.
} 
castigos, paraísos e infiernos, una vez que la existencia ha abierto el juego libre de su deseo.

En breve, después de más de 3000 años de olvido, las Diosas parecen volver de su destierro, con la propuesta de una nueva humanidad, que es en definitiva lo que lx humanx siempre ha sido. Para recuperar la inocencia del devenir, para volver a jugar en paz y reencontrar la identidad que precede a la separación, es urgente y necesario volver a pronunciarnos en el Nombre de la Madre.

\section{Referencias bibliográficas}

BACHOFEn, J. J. (1992): El matriarcado: Una investigación sobre la ginecocracia en el mundo antiguo según su naturaleza religiosa y jurídica, trad. María del Mar Llinares García, Madrid, Akal.

BIRULÉs, F. (1995): El género de la memoria, Pamplona, Pamiela.

Bourdieu, P. (2010): La eficacia simbólica. Religión y politica, trad. Alicia B. Gutiérrez - Ana Teresa Martínez, Buenos Aires, Biblos.

CAputo, J. D. (1997): The Prayers and Tears of Jacques Derrida. Religion without religion, Bloomington - Indianapolis, Indiana University Press.

CAputo, J. D. (2002): The Religious, Malden-Oxford, Blackwell.

Derrida, J. (1999): Donner la mort, Paris, Galilée.

Duby, G. - Perrot, M. - Schmitt Pantel, P. (1994): A History of Women. I: From Ancient Goddesses to Christian Saints, trad. Arthur Goldhammer, Cambridge, Harvard University Press.

Eliade, M. (1975): Mith and Reality, trad. Willard R. Trask, New York, Harper.

GetTy, A. (1990): La Diosa, trad. Flora Casas, Madrid, Debate.

Hölderlin (1979): Poesía Completa, trad. Federico Gorbea, Barcelona, Libros Río Nuevo.

Jaggar, A. A. - Young, I. M. (1998): Companion to Feminist Philosophy, Malden, Blackwell.

Jung, C. G. (1961): Psicología y religión, trad. Ilse T. M. de Brugger, Buenos Aires, Paidós,

JunG, C. G. (1984): El hombre y sus símbolos, trad. Luis Escolar Bareño, Barcelona, Caralt.

LACAN, J. (1992): Seminario VII: La ética del psicoanálisis (1959-60), ed. J. A. Miller, Buenos Aires, Paidós.

Motz, L. (1997): The Faces of the Goddess, New York, Oxford University Press.

Muraro, L. (1994): El orden simbólico de la madre, trad. Beatriz Albertini, Madrid, horas y Horas.

Pomeroy, S. B. (1987): Diosas, rameras, esposas y esclavas. Las mujeres en la antigüedad clásica, trad. Ricardo Lezcano Escudero, Madrid, Akal. 
Preston, J.J., (1982): Mother Worship. Theme \& Variations, Chapel Hill, The University of North Carolina Press.

Schlegel, F. (1958): Fragmentos, trad. E. Uranga, México, Universidad Nacional Autónoma de México.

SJöÖ, M. - Mor, B. (1991): The Great Cosmic Mother: Rediscovering the Religion of the Earth, New York, Harper Collins Publishers.

Stone, M. (1978): When God was a Woman, San Diego, Harcourt Brace.

TRÍAS, E. (2001): Pensar la religión, Buenos Aires, Altamira.

TRíAs, E. (2006): La edad del espíritu, Barcelona, DeBolsillo.

TUBERT, S. (1991): Mujeres sin sombra. Maternidad y tecnología, Madrid, Siglo XXI.

TUBERT, S. (2001): Figuras de la madre, Valencia, Cátedra.

TUBERT S. (2007): Figuras del padre, Madrid, Cátedra.

Whitmont, E. (1982): Return of the Goddess, New York, Crossroad.

María J. Binetti

CONICET - Argentina

mjbinetti@gmail.com 